\title{
Social support moderates stress effects on depression
}

\author{
Xingmin Wang ${ }^{1 \dagger}$, Lin $\mathrm{Cai}^{2+}$, Jing Qian ${ }^{3^{*}}$ and Jiaxi Peng ${ }^{4^{*}}$
}

\begin{abstract}
This study examined the moderator effect of social support on the relationship between stress and depression of university students. A total of 632 undergraduate students completed the measures of perceived stress, perceived social support, and depression. Hierarchical regression analysis showed that social support moderated the association between stress and depression. Undergraduate students with high stress reported higher scores in depression than those with low stress with low social support level. However, the impact of stress on depression was much smaller in the high social support group compared with that in the low social support group.
\end{abstract}

Keywords: Stress, Social support, Depression, Moderating effect, University students

\section{Introduction}

Studies that focus on college students' mental health problems are gradually increasing because of significant increase in the incidence of mental disorder among college students [1-3]. Depression is a common mental disorder mainly characterized by significant and constant down in spirits [4]. Emotional depression varies from moodiness to grief, low self-esteem, depression, and even pessimism, which may lead to suicidal attempt or behavior $[5,6]$. Previous studies have found that depressive symptoms are widespread in college students [7]. Surveys have found that the Chinese mainland college student depression rate is $15 \%$ to $35 \%$ [8-10].

Stress, a mental experience caused by demand and failure, is very common in our lives [5]. However, stress may further cause negative emotions, such as depression and anxiety, and may even hinder normal development of the personality and behavior of a person if not properly controlled and responded to [11]. Depression is created through interaction of various factors, including environmental and individual factors [12]. After summarizing the results obtained from nearly twenty years of research about the relationship between stress and depression, Kessler indicated that stress is closely related with depression and stress intensity and degree of

\footnotetext{
* Correspondence: jingqianbnu@outlook.com; pengjx880124@sina.com

${ }^{\dagger}$ Equal contributors

${ }^{3}$ School of Business, Beijing Normal University, Beijing, China

${ }^{4}$ Department of Psychology, Fourth Military Medical University, Xi'an, China

Full list of author information is available at the end of the article
}

depression have a dose-response relationship [13,14]. However, not all people will have depression when under pressure. The depression degree of different individuals varies even under the same stress conditions $[15,16]$, indicating that other variables affect the relationship between stress and depression.

Social support is the care or help from others that an individual can feel, notice, or accept $[17,18]$. As an important environmental resource in an individual's social life, social support affects a person's physical and mental health and behavior patterns, and has a very close relationship with the generation, development, control, and prevention of depression [19-21]. A good social support can provide protection for an individual under stress and has common gaining function on maintaining an individual's good emotional experience [22].

Existing studies on graduate student groups have focused on mutual relationship among stress, social support, and depression. We consider that the mental mechanism research on depression generation should deeply discuss the cooperation and antagonism between different factors. Based on previous studies, we assume that relationship between stress and depression is affected by social support, a moderating variable between stress and depression.

\section{Methods}

Participants and procedure

The participants included 632 undergraduate students comprising 315 women and 317 men from Chonging 
City, China. The ages of the participants ranged from 18 to 22 years old, with a mean of $20.47(\mathrm{SD}=1.74)$. The participants received $¥ 15$ as compensation. A total of 632 scales were distributed and collected; all scales were valid. All participants provided their written informed consent before completing the measures.

\section{Instruments}

\section{Perceived stress scale}

The Perceived Stress Scale is a self-report instrument that evaluates the level of perceived stress during the past month and consists of 14 items with a 5-point response scale $(0=$ never, $1=$ almost never, $2=$ once in a while, $3=$ often, $4=$ very often). Higher score indicates higher level of perceived stress [23]. In this study, the Cronbach alpha coefficient for Perceived stress Scale was 0.850 .

\section{Perceived social support scale (PSSS)}

PSSS, developed by Zimet et al., is a 12-item self-report measure of how an individual perceives the social support system, including an individual's sources of social support (i.e., family, friends, and significant other). Items are rated from 1 (very strongly disagree) to 7 (very strongly agree) [24]. Three subscale scores for PSSS can be computed, namely, support from family, friends, and significant other. Examples of the items from this form are as follows: "I get the emotional help and support I need from my family" and "My friends really try to help me". PSSS was translated by Chou [25] and has been proven to have good validity and reliability for the Chinese population (e.g., [26]). In the present study, the Cronbach alpha coefficient for PSSS was 0.848 .

\section{Self-rating depression scale (SDS)}

SDS, developed by Zung [27], is a self-report measure of depression consisting of 20 items, with a four-point scale ranging from (1) a little of the time to (4) most of the time. Among the 20 items, 10 are worded positively and 10 are worded negatively. The former 10 items are reversed items. The validity and reliability of the SDS have been reported [27]. The researcher translated the 20-item version of SDS into Chinese, and this version has been proven to have good validity and reliability [28]. In the current study, the Cronbach alpha coefficient for SDS was 0.886 .

\section{Results}

\section{Bivariate analyses}

The means, standard deviations, and inter correlations for each questionnaire are presented in Table 1. According to the SDS norm of Chinese college students, the total SDS score was greater than or equal to 41, which is deemed as the bound of depression [29]. About 18.7\% of
Table 1 Means, standard deviations, and correlations of stress, social support and depression

\begin{tabular}{lccccr}
\hline & Mean & SD & $\mathbf{1}$ & $\mathbf{2}$ & $\mathbf{3}$ \\
\hline 1. Stress & 18.44 & 7.35 & 1 & & \\
2. Social support & 69.12 & 10.14 & $-0.53^{* *}$ & 1 & \\
3. Depression & 11.84 & 11.84 & $0.44^{* *}$ & $-0.45^{* *}$ & 1 \\
\hline
\end{tabular}

Not: $* *, p<0.01$.

the participants had depression. Table 1 shows that stress is negatively correlated with social support and both stress and social support are correlated with depression.

\section{Test of the moderation model of social support}

Hierarchical regression procedures were performed to test the moderating effect of social support on the relationship of stress and depression [30]. The social support and stress variables were standardized before testing for moderating effect to reduce problems related to multicolinearity between the interaction term and the main effects [31]. Thus, the z-scores were calculated for social support and stress. The order of entry in the hierarchical regression model was as follows. At step 1, the predictor variable (stress) was entered into the regression equation. At step 2, the moderator variable (social support) was entered into the regression equation. At step 3, the interaction of stress $\times$ social support was added. The significant change in $\mathrm{R}^{2}$ for the interaction term indicates significant moderator effect. The results of these analyses are presented in Table 2. Stress $(\beta=0.44, \mathrm{p}<0.01)$ significantly predicted depression in the second step. The social support factor added a significant increment to the model in step three, where social support $(\beta=-0.30, p<0.01)$ was significantly related to depression after controlling other variables. Moreover, a significant interaction between stress and social support $(\beta=-0.10, \mathrm{p}<0.01)$ was present, as predicted. These findings suggest that social support moderated the impact of stress on depression.

To illustrate the stress $\times$ social support interaction for depression, we plotted the regression of depression on stress at high and low levels of social support (see Figure 1). Consistent with the procedures outlined by Kong, Zhao, and You [32], we utilized a simple slope

Table 2 Hierarchical regression analysis predicting depression from social support and stress

\begin{tabular}{lccccccc}
\hline & $\mathbf{B}$ & $\mathbf{S E}$ & $\boldsymbol{\beta}$ & $\boldsymbol{t}$ & $\boldsymbol{F}$ & $\mathbf{R}^{\mathbf{2}}$ & $\Delta \mathbf{R}^{\mathbf{2}}$ \\
\hline Step 1 & & & & & & & \\
Stress & 5.16 & 0.43 & 0.44 & 12.16 & 147.89 & 0.189 & 0.189 \\
Step 2 & & & & & & & \\
Social support & -3.59 & 0.48 & -0.30 & -7.50 & 56.24 & 0.254 & 0.066 \\
Step 3 & & & & & & & \\
Stress × Social support & -0.84 & 0.31 & -0.10 & 2.84 & 10.49 & 0.265 & 0.011 \\
\hline
\end{tabular}




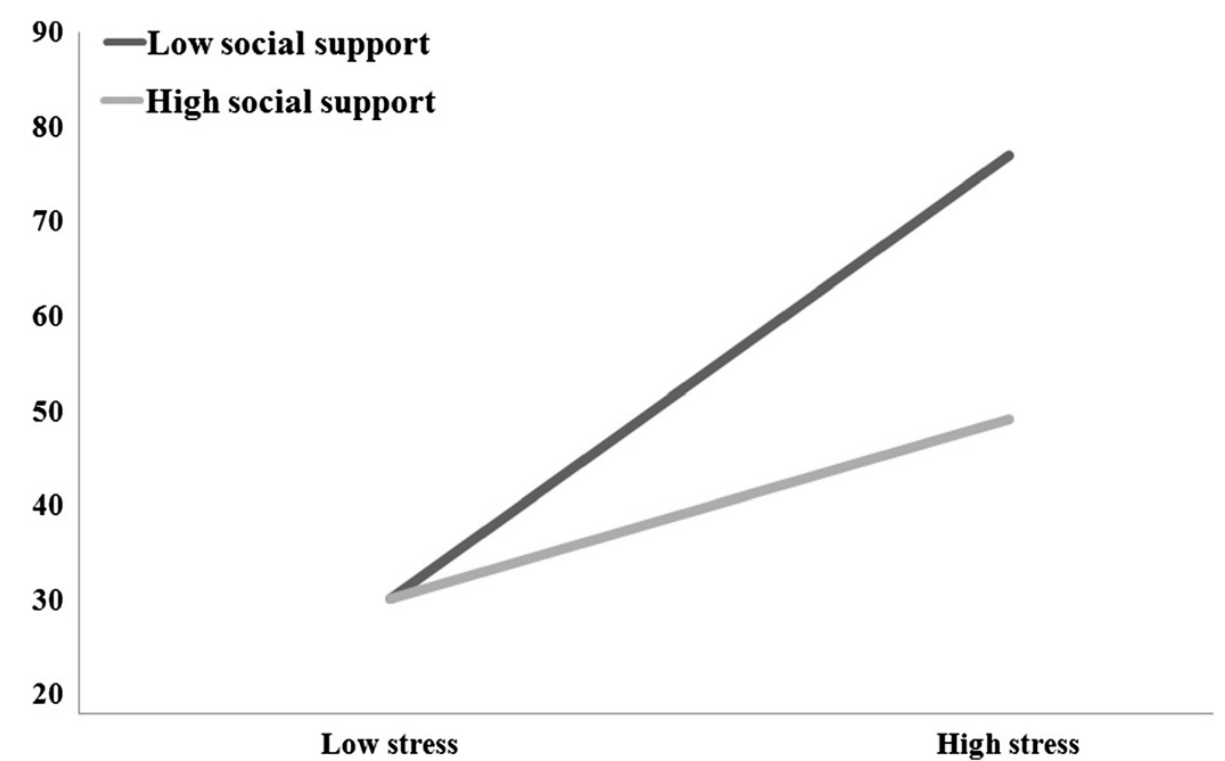

Figure 1 The moderating effect of social support in the relationship between stress and depression.

formula for regression of stress on depression using the high (above the mean) and low (below the mean) values for social support [32]. Figure 1 shows a significantly positive relationship between stress and depression at low levels of social support $\left(\beta=0.47, p<0.01, R^{2}=0.22\right)$. The relationship between stress and depression was significant at high levels of social support $\left(\beta=0.22, \mathrm{p}<0.01, \mathrm{R}^{2}=0.04\right)$. The regression coefficient, however, was significantly less than that in the low social support group. Hence, the results also suggest that social support moderated the impact of stress on depression.

\section{Structural equation modeling analysis}

The SEM unconstrained approach put forward by Marsh, Wen, and Hau was used to test the moderating role of organizational identification on the relationships between organizational justice and job satisfaction [32]. Confirmatory factor analysis was used to assess whether the measurement model adequately fit the sample data. A test of the measurement model yielded

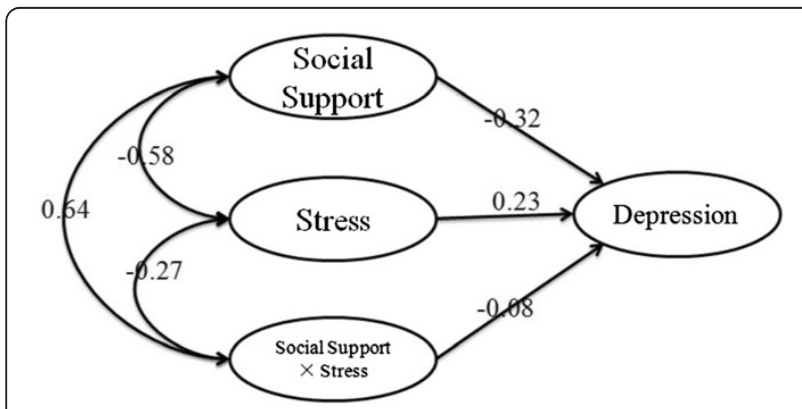

Figure 2 The finalized structural model. satisfactory fit to the data: $\mathrm{X}^{2} / \mathrm{df}=2.16$, RMSEA $=0.071$, SRMR $=0.046$ and CFI $=0.974$. All factor loadings of the indicators of the latent variables were significant $(\mathrm{p}<0.001)$, indicating that all these latent constructs were well represented by their indicators. Thus, a structural model was built (Figure 2). The final moderating model yielded satisfactory fit to the data: $\chi^{2} / \mathrm{df}=1.61$, RMSEA $=$ 0.031, SRMR $=0.015$ and CFI $=0.997$.

\section{Discussion}

According to the SDS norm standard of Chinese college students, the total SDS score was greater than or equal to 41 points, which is deemed as the bound of depression [29]. The detection rate of people with depression was $18.7 \%$, demonstrating that the incidence of depression among the college students is rather high and should be given more attention [9].

The correlation analysis in this research showed that graduate students depression has a significant positive correlation with stress, indicating that stress is an important factor that affects depression generation. The same results were found in previous researches about stress and depression regarding different groups as research objects [15,33,34]. College students are carrying higher expectations from society, family, and individual, and are suffering from various stresses including study, occupation, marriage, and family $[35,36]$. The stresses caused by negative life events may make students depressed, such as heavy burden of study, growing occupation or entrance stress, failure in love, and dispute or misunderstanding with classmates [37-39].

This research found that relationship between stress and depression is affected by social support, compared 
with the team of high social support. A closer relationship was found between stress and depression in the low social support team. Social support plays a significant regulating effect on the relationship between stress and depression and is an important environmental resource [20,40]. An individual's good social support network allows him/her to gain self-esteem and self-efficacy easier, thereby resisting the generation of negative emotions such as depression [41-43]. When an individual is under stress, social support makes him/her underestimate the hazards and the verities of stress by enhancing their coping capacities perceived. Social support can also provide problem solving strategies to the individual, reduce the importance of the problem, and alleviate the harmful effects of stress experience $[42,44,45]$. These effects can reduce the intensity of the relationship between stress and depression, thereby lowering the degree and generation of depression.

The results of this research suggest that the high depressive symptoms among college students should be brought to the attention of relevant departments. To prevent college student depression, relevant departments should both optimize the environment of college student study and life, try to decrease the generation of negative life events, provide adequate social support for college students, and enhance their cognitive and coping capacities to improve their mental qualities.

\section{Competing interests}

The authors declare that they have no competing interests.

\section{Authors' contributions}

Conceived and designed the experiments: XW, LC, JQ and JP. Performed the experiments: XW, JQ and JP. Analyzed the data: XW, LC, JQ and JP. Contributed reagents/materials/analysis tools: JP. Wrote the paper: XW, LC, $J Q$ and JP. All authors read and approved the final manuscript.

\section{Author details}

${ }^{1}$ Anhui Provincial Committee Party School, Hefei, China. ${ }^{2}$ Department of International Exchange and Cooperation, Kunming University, Kunming, China. ${ }^{3}$ School of Business, Beijing Normal University, Beijing, China. ${ }^{4}$ Department of Psychology, Fourth Military Medical University, Xi'an, China.

Received: 12 September 2014 Accepted: 24 October 2014 Published: 13 November 2014

\section{References}

1. Hunt J, Eisenberg D: Mental health problems and help-seeking behavior among college students. J Adolesc Health 2010, 46(1):3-10.

2. Braithwaite SR, Delevi R, Fincham FD: Romantic relationships and the physical and mental health of college students. Pers Relat 2010, 17(1):1-12.

3. Moreno MA, Jelenchick LA, Egan KG, Cox E, Young H, Gannon KE, Becker T: Feeling bad on facebook: depression disclosures by college students on a social networking site. Depress Anxiety 2011, 28(6):447-455.

4. Rytwinski NK, Avena JS, Echiverri-Cohen AM, Zoellner LA, Feeny NC: The relationships between posttraumatic stress disorder severity, depression severity and physical health. J Health Psychol 2014, 19(4):509-520.

5. Bennett KS, Shepherd JM: Depression in Australian women: the varied roles of spirituality and social support. J Health Psychol 2013, 18(3):429-438.

6. Hochberg MS, Berman RS, Kalet AL, Zabar SR, Gillespie C, Pachter HL: The stress of residency: recognizing the signs of depression and suicide in you and your fellow residents. Am J Surg 2013, 205(2):141-146.
7. Ibrahim AK, Kelly SJ, Adams CE, Glazebrook C: A systematic review of studies of depression prevalence in university students. J Psychiatr Res 2013, 47(3):391-400.

8. Meng H, Li J, Loerbroks A, Wu J, Chen H: Rural/urban background, depression and suicidal ideation in Chinese college students: a cross-sectional study. PLoS One 2013, 8(8):e71313.

9. Chen L, Wang L, Qiu XH, Yang XX, Qiao ZX, Yang YJ, Liang Y: Depression among Chinese university students: prevalence and socio-demographic correlates. PLoS One 2013, 8(3):e58379.

10. BI Z, Ding J, Chen H, Li Y, Xu H, Tong J, Wang A, Tang G, Zhu J, Yang D: Depressive disorders among children in the transforming China: an epidemiological survey of prevalence, correlates, and service use. Depress Anxiety 2013, 30(9):881-892.

11. Peng J, Xiao W, Yang Y, Wu S, Miao D: The impact of trait anxiety on self-frame and decision making. J Behav Decis Mak 2014, 27(1):11-19.

12. Hammen C, Hazel NA, Brennan PA, Najman J: Intergenerational transmission and continuity of stress and depression: depressed women and their offspring in 20 years of follow-up. Psychol Med 2012, 42(05):931-942.

13. Kessler RC: Epidemiology of women and depression. J Affect Disord 2003, 74(1):5-13.

14. Kessler RC: Posttraumatic stress disorder: the burden to the individual and to society. J Clin Psychiatry 2000, 61:4-14.

15. Jaremka LM, Lindgren ME, Kiecolt-Glaser JK: Synergistic relationships among stress, depression, and troubled relationships: insights from psychoneuroimmunology. Depress Anxiety 2013, 30(4):288-296.

16. O'Connor SS, Zatzick DF, Wang J, Temkin N, Koepsell TD, Jaffe KM, Durbin D, Vavilala MS, Dorsch A, Rivara FP: Association between posttraumatic stress, depression, and functional impairments in adolescents 24 months after traumatic brain injury. J Trauma Stress 2012, 25(3):264-271.

17. Wang $X$ : Subjective well-being associated with size of social network and social support of elderly. J Health Psychol 2014, doi:1359105314544136.

18. He F, Guan H, Kong Y, Cao R, Peng J: Some individual differences influencing the propensity to happiness: Insights from behavioral economics. Soc Indic Res 2014, 119:897-908.

19. Peng J, Miao D, Xiao W: Why are gainers more risk seeking. Judgment Decis Making 2013, 8(2):150-160.

20. Thoits PA: Mechanisms linking social ties and support to physical and mental health. J Health Soc Behav 2011, 52(2):145-161.

21. Thoits PA: Perceived social support and the voluntary, mixed, or pressured use of mental health services. Soc Mental Health 2011, 1(1):4-19.

22. Maulik PK, Eaton WW, Bradshaw CP: The effect of social networks and social support on mental health services use, following a life event, among the Baltimore Epidemiologic Catchment Area cohort. J Behav Health Serv Res 2011, 38(1):29-50.

23. Cohen S: Contrasting the hassles scale and the perceived stress scale: who's really measuring appraised stress? Am Psychol 1986, 41:716-718.

24. Zimet GD, Dahlem NW, Zimet SG, Farley GK: The multidimensional scale of perceived social support. J Person Assess 1988, 52(1):30-41.

25. Chou KL: Assessing Chinese adolescents' social support: the multidimensional scale of perceived social support. Person Individ Differ 2000, 28(2):299-307.

26. Kong F, You X: Loneliness and self-esteem as mediators between social support and life satisfaction in late adolescence. Soc Indicat Res 2013, 110(1):271-279.

27. Zung WW: A self-rating depression scale. Arch Gen Psychiatr 1965, 12(1):63-70.

28. Lee HC, Chiu HFK, Wing YK, Leung CM, Kwong PK, Chung DWS: The Zung self-rating depression scale: screening for depression among the Hong Kong Chinese elderly. J Geriatr Psychiatry Neurol 1994, 7(4):216-220.

29. Ni X, Yan H, Chen S, Liu Z: Factors influencing internet addiction in a sample of freshmen university students in China. Cyberpsychol Behav 2009, 12(3):327-330.

30. Baron RM, Kenny DA: The moderator-mediator variable distinction in social psychological research: conceptual, strategic, and statistical considerations. J Pers Soc Psychol 1986, 51(6):1173-1182.

31. Frazier PA, Tix AP, Barron KE: Testing moderator and mediator effects in counseling psychology research. J Couns Psychol 2004, 51(1):115-134.

32. Kong F, Zhao J, You X: Self-esteem as mediator and moderator of the relationship between social support and subjective well-being among Chinese university students. Soc Indic Res 2013, 112(1):151-161. 
33. Anacker C, Cattaneo A, Musaelyan K, Zunszain PA, Horowitz M, Molteni R, Luoni A, Calabrese F, Tansey K, Gennarelli M: Role for the kinase SGK1 in stress, depression, and glucocorticoid effects on hippocampal neurogenesis. Proc Natl Acad Sci 2013, 110(21):8708-8713.

34. Peng J, Jiang X, Zhang J, Xiao R, Song Y, Feng X, Zhang Y, Miao D: The impact of psychological capital on job burnout of Chinese nurses: the mediator role of organizational commitment. PLoS One 2013, 8(12):e84193.

35. Peng J, Jiang Y, Miao D, Li R, Xiao W: Framing effects in medical situations: distinctions of attribute, goal and risky choice frames. J Int Med Res 2013, 41(3):771-776.

36. Regehr C, Glancy D, Pitts A: Interventions to reduce stress in university students: a review and meta-analysis. J Affect Disord 2013, 148(1):1-11.

37. Lee DS, Padilla AM: Acculturative stress and coping: gender differences among Korean and Korean American university students. J Coll Stud Dev 2014, 55(3):243-262.

38. Park YR, Jang EH: Impact of stress on depression among university students: testing for moderating effect of social support. Korean J Adult Nurs 2013, 25(5):549-558.

39. Chai PPM, Krägeloh CU, Shepherd D, Billington R: Stress and quality of life in international and domestic university students: cultural differences in the use of religious coping. Mental Health Relig Cult 2012, 15(3):265-277.

40. Fagundes CP, Lindgren ME, Shapiro CL, Kiecolt-Glaser JK: Child maltreatment and breast cancer survivors: social support makes a difference for quality of life, fatigue and cancer stress. Eur J Cancer 2012, 48(5):728-736.

41. Kossek EE, Pichler S, Bodner T, Hammer LB: Workplace social support and work-family conflict: a meta-analysis clarifying the influence of general and work-family-specific supervisor and organizational support. Pers Psychol 2011, 64(2):289-313.

42. Barth J, Schneider S, von Känel R: Lack of social support in the etiology and the prognosis of coronary heart disease: a systematic review and meta-analysis. Psychosom Med 2010, 72(3):229-238.

43. Lee C, Dickson DA, Conley CS, Holmbeck GN: A closer look at self-esteem, perceived social support, and coping strategy: a prospective study of depressive symptomatology across the transition to college. J Soc Clin Psychol 2014, 33(6):560-585.

44. Kim J-M, Stewart R, Kim S-W, Kang H-J, Kim S-Y, Lee J-Y, Bae K-Y, Shin I-S, Yoon J-S: Interactions between a serotonin transporter gene, life events and social support on suicidal ideation in Korean elders. J Affect Disord 2014, 160:14-20.

45. Waite EB, Shanahan L, Calkins SD, Keane SP, O'Brien M: Life events, sibling warmth, and youths' adjustment. J Marriage Fam 2011, 73(5):902-912.

doi:10.1186/1752-4458-8-41

Cite this article as: Wang et al:: Social support moderates stress effects on depression. International Journal of Mental Health Systems 2014 8:41.

\section{Submit your next manuscript to BioMed Central and take full advantage of:}

- Convenient online submission

- Thorough peer review

- No space constraints or color figure charges

- Immediate publication on acceptance

- Inclusion in PubMed, CAS, Scopus and Google Scholar

- Research which is freely available for redistribution 